\title{
Spotlight on available optical properties and models of nanofluids: A review
}

\author{
Mohammad Sajid Hossain ${ }^{\text {a,* }}$, R. Saidur ${ }^{\text {a,b }}$, Mohd Faizul Mohd Sabri ${ }^{\text {a }}$, \\ Z. Said ${ }^{\mathrm{a}, \mathrm{c}}$, Samir Hassani ${ }^{\mathrm{a}}$ \\ a Department of Mechanical Engineering, Faculty of Engineering, University of Malaya, 50603 Kuala Lumpur, Malaysia \\ ${ }^{\mathrm{b}}$ UM Power Energy Dedicated Advanced Center (UMPEDAC), University of Malaya, 59990 Kuala Lumpur, Malaysia \\ 'Department of Engineering Systems and Management (ESM), Masdar Institute of Science and Technology, P.O. Box 54224, Abu Dhabi, United Arab Emirates
}

A R T I C L E I N F O

\section{Article history:}

Received 4 July 2013

Received in revised form

27 September 2014

Accepted 2 November 2014

Available online 5 December 2014

Keywords:

Nanofluids

Optical properties

Theoretical models

Extinction

Scattering

Absorption
A B S T R A C T

Optical characteristics besides unique thermo-physical properties of nanoparticles have encouraged researchers to use nanofluids in solar energy collectors or reservoirs as electromagnetic wave absorbing media. Recently, different analyses and approaches have been proposed by researchers. However, the appropriate electro-magnetic phenomenon of nanofluids is not established till date because of the complex dependence between nanoparticles and base fluids. In this work, optical properties of nanofluids are discussed on the basis of published data; mostly used models are presented along with their limitations and applications.

c) 2014 Elsevier Ltd. All rights reserved.

Contents

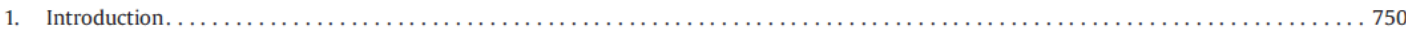

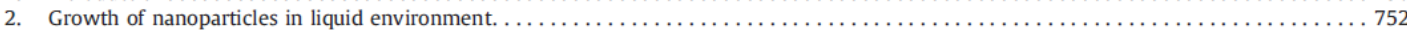

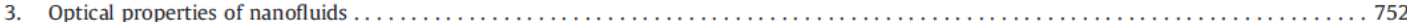

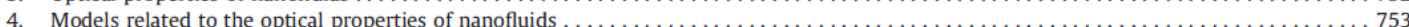

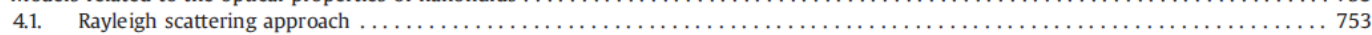

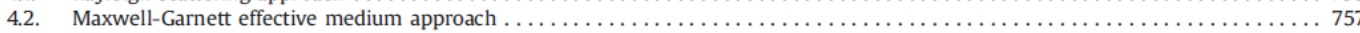

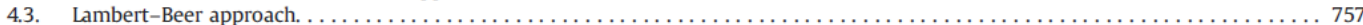

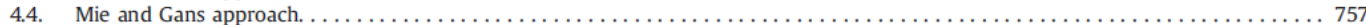

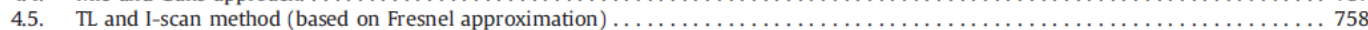

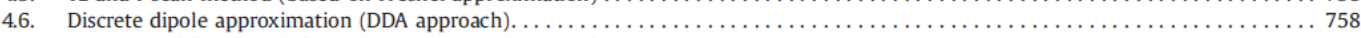

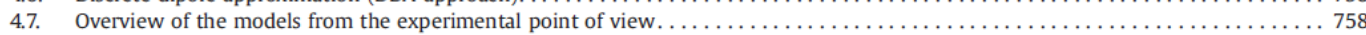

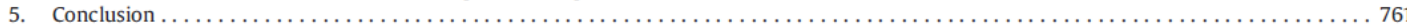

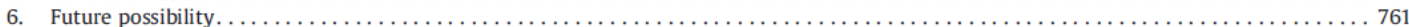

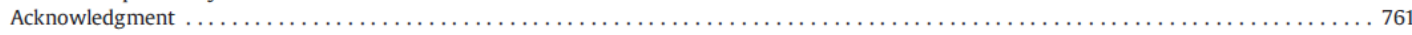

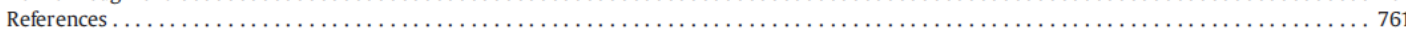

\footnotetext{
*Corresponding author. Tel.: +60379677611 .

E-mail addresses: saj0205037@yahoo.com (M. Sajid Hossain), saidur@um.edu.my (R. Saidur), faizul@um.edu,my (M.F. Mohd Sabri), zaffar_14@yahoo.com (Z Said), samietude@yahoo.fr (S. Hassani).

http://dx.doi.org/10.1016/j.rser.2014.11.010

1364-0321/o 2014 Elsevier Ltd. All rights reserved.
}

\section{Introduction}

Nanofluids, having remarkable enhancement in heat transfer capacity, are attracting researchers to implement them in solar cultivating systems. Nanoparticles are found to be very good 


\begin{tabular}{|c|c|c|c|}
\hline \multicolumn{2}{|c|}{ Nomenclature } & \multirow{2}{*}{$\begin{array}{l}\lambda_{\mathrm{p}} \\
\mu_{\mathrm{a}}, \mu_{\mathrm{s}}\end{array}$} & \multirow{2}{*}{$\begin{array}{l}\text { wavelength of probe beam } \\
\text { absorption and scattering coefficients of suspension/ } \\
\text { nanofluids, respectively }\end{array}$} \\
\hline$A$ & absorbance of the sample & & \\
\hline D & diameter of nanoparticles & $\mu_{\mathrm{s}}{ }^{\prime}$ & reduced scattering coefficient of the medium \\
\hline DDW & double distilled water & $\mu_{\mathrm{eff}}$ & effective attenuation coefficient of the medium \\
\hline E & energy of the pulse & $\mu_{\text {ext,particle }}$ & les extinction coefficient of nanoparticles \\
\hline EG, PG & ethylene glycol, propylene glycol & $\mu_{\text {ext,baseflu }}$ & uid extinction coefficient of base fluid \\
\hline G & experimental geometrical factor & $\mu_{\text {ext,total }}$ & extinction coefficient of nanofluid \\
\hline$I_{0}, I(r)$ & $\begin{array}{l}\text { intensity of incident light and intensity at distance ' } r \text {,' } \\
\text { respectively }\end{array}$ & $\sigma_{\mathrm{ext}}, \sigma_{\mathrm{s}}, \sigma_{\mathrm{a}}$ & $\begin{array}{l}\text { axtinction, scattering and absorption cross-sections of } \\
\text { suspension, respectively }\end{array}$ \\
\hline$N$ & number of scattering particles in the beam path & $\tau$ & thermal diffusivity \\
\hline NPs & nanoparticles & $\Phi$ & fluence rate \\
\hline$Q_{\text {ext }}, Q_{\mathrm{a}}$, & $\begin{array}{l}Q_{s} \text { extinction, absorption and scattering efficiencies, } \\
\text { respectively }\end{array}$ & $\omega_{0}, \omega_{\mathrm{p}}$ & $\begin{array}{l}\text { diameter of the probe beam at source and at sample } \\
\text { positions, respectively }\end{array}$ \\
\hline$R$ & radius of particles & $a_{\mathrm{n},}, b_{\mathrm{n}}$ & defined factors \\
\hline TLS & thermal lens signal & $d n / d T$ & thermo-optical coefficient of the sample (nanofluids) \\
\hline$V$ & volume of particle & $e$ & thermal effusivity \\
\hline$\alpha$ & non-dimensional particle size parameter & $f_{\mathrm{v}}$ & volume fraction \\
\hline$\varepsilon_{\text {eff, }} \varepsilon_{\mathrm{p}}, \varepsilon_{\mathrm{t}}$ & $\begin{array}{l}\text { fielectric constant of nanofluids, nanoparticles and } \\
\text { base fluid, respectively }\end{array}$ & $\begin{array}{l}g \\
k\end{array}$ & $\begin{array}{l}\text { anisotropy factor of the scattering function } \\
\text { complex component of refractive index }\end{array}$ \\
\hline$\varepsilon^{\prime}, \varepsilon^{\prime \prime}$ & $\begin{array}{l}\text { real and complex components of dielectric constant, } \\
\text { respectively }\end{array}$ & $\begin{array}{l}m \\
n\end{array}$ & $\begin{array}{l}\text { relative complex refractive index of nanofluid } \\
\text { real component of refractive index }\end{array}$ \\
\hline$\varepsilon$ & $\begin{array}{l}\text { complex dielectric constant of particles (bulk } \\
\text { material) }\end{array}$ & $\begin{array}{l}n_{\mathrm{m}} \\
n_{\mathrm{p}}\end{array}$ & $\begin{array}{l}\text { refractive index of medium/base fluid } \\
\text { refractive index of particles }\end{array}$ \\
\hline$\varepsilon_{\mathrm{m}}$ & dielectric constant of medium/base fluid & $r$ & distance measured from the source of light \\
\hline$\theta$ & scattering angle & $z$ & special co-ordinate \\
\hline$\kappa$ & thermal conductivity & $z_{1}$ & distance between the sample and aperture plane \\
\hline$\lambda$ & wavelength of incident light & $z_{\mathrm{c}}$ & Rayleigh range \\
\hline
\end{tabular}

electromagnetic wave absorbers within UV-visible range where $85 \%$ of solar energy is dissolved. On the other hand, conventional base fluids absorb the energy laid within infrared region having $15 \%$ of solar energy. In this work, published optical parameters for nanofluids are discussed along with recently developed models for nanofluids based on the Rayleigh's scattering theory, MaxwellGarnett theory and Mie and Gans theory with their mathematical formulations. An overview on the discussed models is also drawn for comparison and investigation for a well-defined model. The aim of this article is to obtain a clear picture of the available optical properties and models in order to estimate the optical properties of nanofluids properly.

The change in the properties of nano-scale materials compared to their bulk might be for their individual atoms. In a nanoparticle, the amount of surface area is larger compared to its volume. This means that there are more atoms on the surface of the particle than inside it and this leads to increase in specific surface energy. For example, in a palladium nanoparticle $1.2 \mathrm{~nm}$ in diameter, $76 \%$ of the atoms are on the surface of the nanoparticle [1]. Surface atoms act otherwise compared to inner atoms. So, nanoparticles become thermodynamically unstable and have high surface energy when the surface-to-volume ratio increases [2], which makes them a good carrier of energy. A combination of nanoparticles and base fluid as colloidal working medium is expected to have a high impact on the efficiency of solar cultivating systems. A lot of investigations are now run by the researchers all around the world to find out the fundamental optical properties of nanoparticles but few works have been done on nanofluids. Enhancement in the efficiency of various amounts is reported by researchers for different types of solar cultivating systems with nanofluids such as $3 \%$ and $5 \%$ by Otanicar et al. [3] for direct solar absorber with graphite $(30 \mathrm{~nm})$ and silver $(20 \mathrm{~nm})$ nanofluids relative to flat solar collector with water as working medium, respectively; $5 \%-10 \%$ by Taylor et al. [4] for dish solar receiver with graphite nanofluid relative to conventional fluid; $28.3 \%$ by Yousefi et al. [5] for flat plate solar collector with $\mathrm{Al}_{2} \mathrm{O}_{3} / \mathrm{H}_{2} \mathrm{O}$ nanofluids relative to conventional fluid; Kameya and Hanamura [6] have also reported $\mathrm{Ni}$ nanofluid as a good working fluid for solar collectors. Risi et al. de Risi, Milanese [7] conducted a numerical study on a solar Transparent Parabolic Through Collector (TPTC) with gas-based nanofluid as the working fluid; the maximum solar-to-thermal efficiency of the TPTC was found to be equal to $62.5 \%$. Based on experimental investigation on the thermal properties of carbon black aqueous nanofluids for solar absorption, Han et al. [8] have reported a temperature increase from $24.4^{\circ} \mathrm{C}$ to $38.4{ }^{\circ} \mathrm{C}$ of the $6.6 \mathrm{vol} . \%$ nanofluid,within $42 \mathrm{~min}$, with that of water reaching only $31.2{ }^{\circ} \mathrm{C}$.

Lot of research efforts have been devoted to optical properties of nanofluids by many researchers. Optical characterization and mathematical modeling for estimating optical properties (absorption, scattering and extinction coefficients, refractive index, etc.) have been done for $\mathrm{Al}, \mathrm{Ag}, \mathrm{Cu}, \mathrm{Pt}$ and Graphite in water and therminol VP-1 [4], SWCNHs-water [9,10], Ni-Alkyl naphthalene [6] nanofluids. Dependence of scattering and refractive index of nanofluids on volume fraction and size of nanoparticles was investigated by Prasher and Phelan [11] theoretically. A technique, based on TLS and I-scan, has been proposed for thermo-optical properties estimation and demonstrated for Au-water nanofluids by Ortega et al. [12]. In order to evaluate the scattering and absorption efficiency of gold nanorod nanofluid theoretically, Jeon J et al. [13] have used Discrete Dipole Approximation (DDA). There are similar works on it in medical science literatures as well. However, obtained data for optical properties of nanofluids still are not enough for practical implementation and modeling as they are not free from controversy statements. Furthermore, dependence of nanofluids on size, shape, dielectric constant, dipole moment, surface charge, free and bond electrons, electrostatic repulsive force, substrates, concentration, distribution, etc. of nanoparticles as well 
a

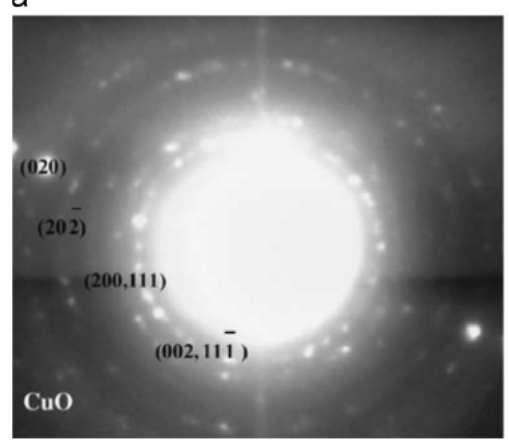

b

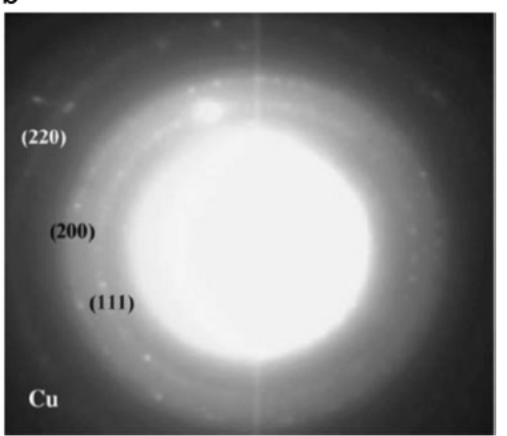

Fig. 1. Electron diffraction pattern of colloidal Cu nanoparticle synthesized in (a) water and (b) acetone. In water, $\mathrm{Cu}$ is oxidized and surrounded by 4 layers, on the other hand in acetone it is surrounded by 3 layers [14].

as temperature distribution and thermo-physical properties of surrounding medium need to be properly correlated and analyzed to describe the optical phenomenon of nanofluids.

\section{Growth of nanoparticles in liquid environment}

The behavior of nanoparticles is environment dependent. The optical properties of nanofluids highly depend on the size of nanoparticles. In liquid environment, they are surface charged and the charge depends on the nature of the environment According to Tilaki et al. [14], an electrical double layer surrounds the nanoparticles because of the interaction of the surface charged particles and the liquid molecules. Plume-nanoparticles interaction also takes place just after dispersing the particles. This interaction leads the nanoparticles to grow to agglomerate. This growth happens in two stages, firstly, the direct self-nucleation of the particles in the condensed plume environment, and secondly, the entertaining behavior to the foreign materials as a growth center. The plume-nanoparticles attraction depends on the repulsive electrostatic and Van der Waals force that introduces elec trical double layer and the attraction between the plume with nanoparticles and nanoparticles with nanoparticles. The growth rate of the nanoparticles can be controlled through the number of the particles into the medium and the dipole moment of the medium. Molecules of the medium with high dipole moment create a stronger bond with the particle surfaces making less room for further foreign material attraction towards the particles. The growth of $\mathrm{Cu}$ in water is much more than that in acetone which makes $\mathrm{Cu}$-water nanofluids completely precipitated in 15 days whereas $\mathrm{Cu}$-acetone remains stable for 10 months as reported by Telaki et al. Their electron diffraction pattern is shown in Fig. 1.

As the properties of nanofluids, thermal or optical, are inversely proportional to the time duration of the stability of nanofluids, it is an important task to take the stability of nanofluids into account. As long as the nanoparticles remain stable in the solution, the quality of nanofluids in terms of optical or thermal properties stays excellent. Recently, Hordy et al. [15] produced a stable dispersion using plasma functionalized MWCNTs, consequently the absorption of nanofluids remains excellent for 8 months in the case of MWCNTs/propylene glycol nanofluids.

\section{Optical properties of nanofluids}

Extinction coefficient is the imaginary component of complex refractive index. It is dependent on the size and nature of the nanoparticle, dielectric constant of the medium and temperature distribution and number of nanoparticles in a system. Different theories have been developed to describe the optical characteristics of nanoparticles till date, such as Refs. [4,16,17], etc. Extinction counts the effects of both absorption and scattering. Absorption is characterized by the intensity loss of the incident light when passing through the working medium. In nanofluids, absorption is for both base fluid and nanoparticles. Because of the strange type of behavior of nanoparticles in working medium it is not just simple summation of their absorption capacity for the nanofluids. Scattering, on the other hand, is also a loss of intensity of incident light caused by the obstacle molecules in the medium which force the incident light to be deviated from its straight trajectory. It is also found that for the nanoparticles having radius $<10 \mathrm{~nm}$. scattering effect is not present but with the increase in size scattering becomes important [18] (for more details see Section 4). For silver nanoparticle in water suspension, scattering increasingly becomes equal to absorption at a particle size of $52 \mathrm{~nm}$ and it increases for the further growth of the particle [19].

The dielectric constant of the surrounding medium and the presence of substrates on nanoparticle surface can change the peak positions of surface plasmon resonance of the plasmonic or metaplasmonic nanoparticles. Their plasmonic absorption and scattering may also be shifted differently when they are dispersed in a medium. Mahmoud et al. [20] studied the effect of surrounding medium and substrates (of quartz) on $\mathrm{Ag}$ nano-cubes of $60 \mathrm{~nm}$ size and found optical spactra of different peaks and ranges. The effect of solvents on optical spectra for $\mathrm{Ag}$ nano-cubes on the surface of the quartz substrate is shown in Fig. 2. Plasmon bandwidth also depends on the particle's size and surrounding temperature. It has been reported that plasmon bandwidth decreases with the increase of Au particle size up to a mean diameter of $25 \mathrm{~nm}$ and increases for a further increase of particle mean diameter in aqueous solution [21]. For Al-water colloidal solution, no effect is found for the spherical particles under $20 \mathrm{~nm}$ diameter on extinction/absorption coefficient but it increases or the spectrum shifts upward with the increase in concentration [22].

Light absorption in fluid introduces the temperature gradient which redistributes the nanoparticles and changes its concentration in the fluid affecting the fluid's surface tension [23]. This rearrangement of nanoparticles may also affect the thermal conductivity, viscosity, etc. of the fluid. Increase in the temperature of the fluid by light absorption decreases the refractive index rather than changing the concentration of the fluid. Some published optical spectra of the nanofluids at room temperature $\left(25^{\circ} \mathrm{C}\right)$ are 


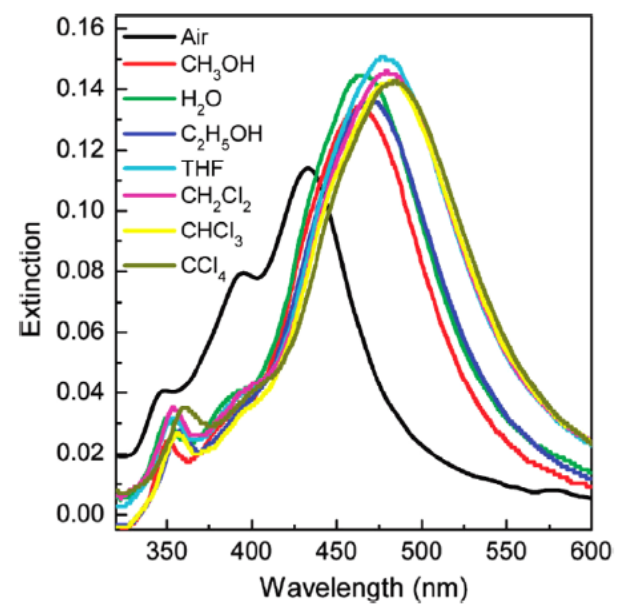

Fig. 2. Surface plasmon resonance spectra of $\mathrm{Ag}$ nano-cubes assembled on the surface of quartz substrate in different surrounding mediums [20]. shown in Fig. 3. A summary is drawn in Table 1 to present the optical characterization works on nanofluids till date. Table 2 shows the summary of the application of nanofluids in solar collectors. Fig. 4.

The design of nanofluids requires the properties of base fluids and nanoparticles. Some published extinction index and refractive index values are included in Tables 3-5 for reference.

\section{Models related to the optical properties of nanofluids}

Different approaches are being taken by the researchers to find out a best fitted mathematical theory for describing the optical properties of nanofluids as the properties do not follow the classical theories. The current approaches for the purpose are discussed in the following sections.

\subsection{Rayleigh scattering approach}

To find out extinction coefficient as well as refractive index of a nanofluid, Taylor, et al. have proposed a theoretical model based on Rayleigh scattering approach [4]. During the model
A

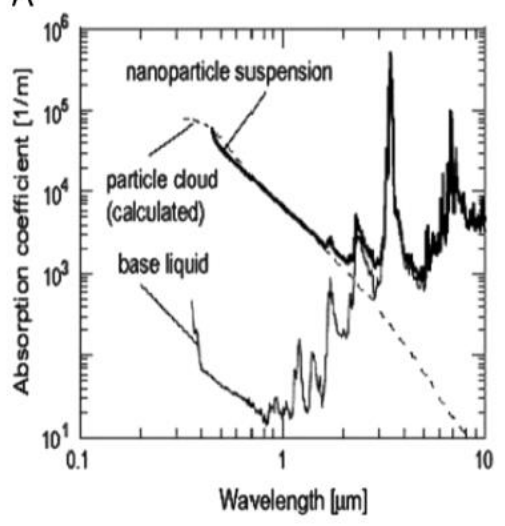

B

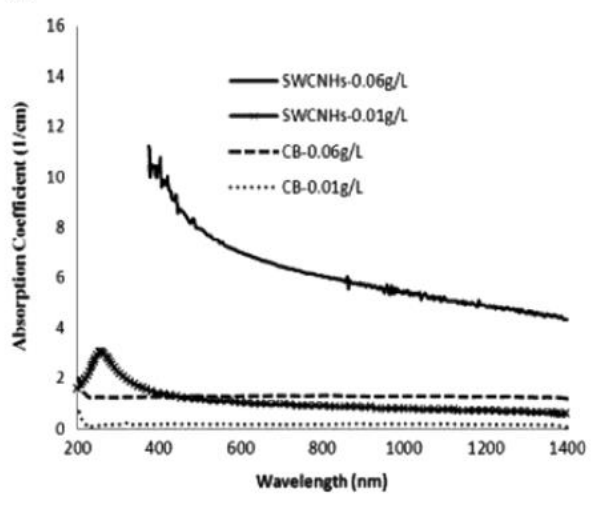

C

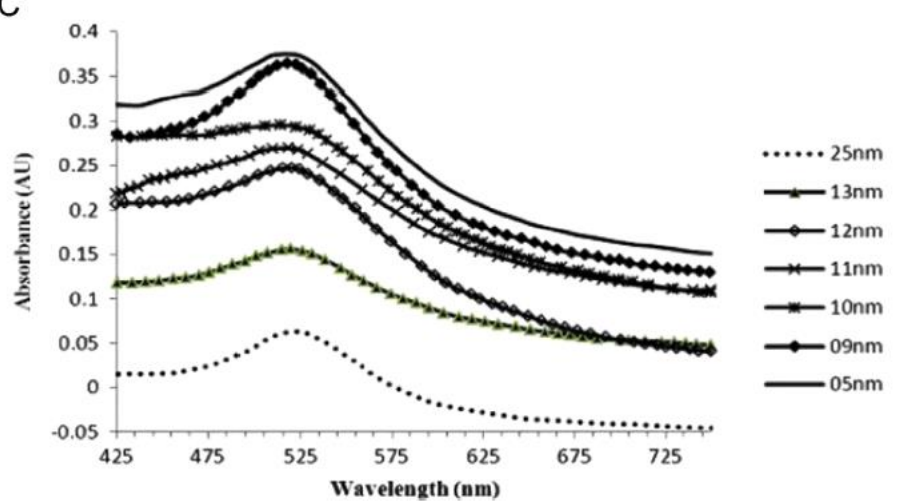

Fig. 3. Absorbance coefficient vs. wavelength for (A) Ni/alkyl naphthalene nanofluid with the nanoparticles and base fluid. Concentration of the solution was 1.0 wt\% and average size of nanoparticles was $4.9 \mathrm{~nm}$ (as obtained from Ref. [6]). (B) SWNCHs/ethylene glycol and carbon black/ethylene glycol nanofluids with $100 \mathrm{~nm}$ NHs and $355 \mathrm{~nm}$ $\mathrm{CBs}$ of mentioned concentrations (regenerated from the results given by Ref. [10]); (C) absorbance vs. wavelength graph for Au/water nanofluids with different nanoparticle sizes (regenerated as per data of Ref. [24]). 
Table 1

Works on optical characterization of nanofluids.

\begin{tabular}{|c|c|c|c|c|c|}
\hline Nanofluid(s) & $\begin{array}{l}\text { Size of NPs } \\
(\mathrm{nm})\end{array}$ & Concentration & Temp. & Optical characterization/enhancement in solar collector efficiency & Ref. \\
\hline $\begin{array}{l}\text { SWCNHs-water with } \\
1.2-1.8 \mathrm{~g} / 1 \mathrm{SDS}\end{array}$ & 100 & $0.3 \mathrm{~g} / 1$ & $\begin{array}{l}\text { Room } \\
\text { temp. }\end{array}$ & Scattering $\leq 5 \%$ and absorption $\geq 95 \%$ & [41] \\
\hline Au-water with SDS & $5-25$ & $\mathrm{n} / \mathrm{a}$ & $\begin{array}{l}\text { Room } \\
\text { temp. }\end{array}$ & $\begin{array}{l}\text { Absorbance peaks occurred at around } 520 \mathrm{~nm} \text { wavelengths and shifted vertically upward with } \\
\text { the decrease in size of NPs. }\end{array}$ & [12] \\
\hline $\mathrm{Cu}$-deionized water & 30 & $\mathrm{n} / \mathrm{a}$ & $\begin{array}{l}\text { Room } \\
\text { temp. }\end{array}$ & $\begin{array}{l}\text { The extinction peak was shifted from around } 600 \mathrm{~nm} \text { to around } 400 \mathrm{~nm} \text { wavelength after } 15 \\
\text { days. }\end{array}$ & {$[14]$} \\
\hline \multirow[t]{3}{*}{ Graphite-water } & \multirow[t]{3}{*}{30} & $0.5 \mathrm{vol} \%$ & \multirow[t]{3}{*}{$\begin{array}{l}\text { Room } \\
\text { temp. }\end{array}$} & $\begin{array}{l}\text { Extinction coefficient decreases from } 3.01 \mathrm{~cm}^{-1} \text { to } 2.61 \mathrm{~cm}^{-1} \text { with the increase in wavelength } \\
(\leq 1100 \mathrm{~nm}) \text {. }\end{array}$ & [4] \\
\hline & & $0.1 \mathrm{vol \%}$ & & $\begin{array}{l}\text { Extinction coefficient decreases from } 2.2 \mathrm{~cm}^{-1} \text { to } 1.77 \mathrm{~cm}^{-1} \text { with the increase in wavelength } \\
(\leq 1400 \mathrm{~nm}) \text {. }\end{array}$ & \\
\hline & & 0.0025 vol\% & & $\begin{array}{l}\text { Extinction coefficient decreases from } 1.36 \mathrm{~cm}^{-1} \text { to } 0.93 \mathrm{~cm}^{-1} \text { with the increase in wavelength } \\
(\leq 1100 \mathrm{~nm}) \text {. }\end{array}$ & \\
\hline $\mathrm{Ag}$-water & 20 & 0.004 vol\% & & $\begin{array}{l}\text { Extinction coefficient decreases from } 1.83 \mathrm{~cm}^{-1} \text { to } 0.29 \mathrm{~cm}^{-1} \text { with the increase in wavelength } \\
(400 \mathrm{~nm}-1300 \mathrm{~nm}) \text {. }\end{array}$ & \\
\hline MWCNTs-Ethanol & 20 & $0.1 \mathrm{wt} \%$ & - & $\begin{array}{l}\text { The extinction coefficient decreases from } 107 \mathrm{~cm}^{-1} \text { to } 22 \mathrm{~cm}^{-1} \text { with the increase in wavelength } \\
(\leq 900)\end{array}$ & {$[42]$} \\
\hline MWCNTs-water & 53 & $\begin{array}{l}0.0005- \\
0.005 \text { vol\% }\end{array}$ & - & $\begin{array}{l}\text { Extinction coefficient linearly increases from } 0.6 \mathrm{~cm}^{-1} \text { to } 3.83 \mathrm{~cm}^{-1} \text { with the increase in volume } \\
\text { fraction within } 632.8 \mathrm{~nm} \text { wavelength }\end{array}$ & {$[43]$} \\
\hline
\end{tabular}

Table 2

Nanofluids in solar collectors.

\begin{tabular}{|c|c|c|c|c|}
\hline Nanofluid(s) & $\begin{array}{l}\text { Size }(\mathrm{nm}) \\
\text { and shape }\end{array}$ & Concentration & Enhancement in efficiency & Ref. \\
\hline $\begin{array}{l}\text { MWNT-DDW with Triton X-100 at } \\
\text { surfactant to CNT ratio } 1: 350\end{array}$ & $10-30$ & $\begin{array}{l}0.2 \mathrm{wt} \% \text { and } \\
0.4 \mathrm{wt} \%\end{array}$ & $\begin{array}{l}\text { For } 0.2 \mathrm{wt} \% \text {, decrease in efficiency observed without surfactant whereas for } 0.4 \mathrm{wt} \% \text { increase in } \\
\text { efficiency was noticed. }\end{array}$ & [44] \\
\hline Graphite-therminol VP1 & $\begin{array}{l}20 / \\
\text { Spherical }\end{array}$ & 0.125 vol\% & Enhancement in efficiency of $11 \%$ over the base fluid & [45] \\
\hline Ag-DI Water & $\sim 10$ & $\begin{array}{l}6.5 \mathrm{ppm} \text {, by } \\
\text { volume }\end{array}$ & $\begin{array}{l}\text { Up to } 144 \% \text { enhancement in the stored thermal energy can be obtained at the peak } \\
\text { temperature. }\end{array}$ & [46] \\
\hline Graphite-oil & 35 & 0.01 vol\% & $\begin{array}{l}\text { For an inlet velocity of } \sim 0.000063 \mathrm{~m} / \mathrm{s} \text {, the solar collector efficiency has been improved by } \\
25 \% \\
\text { The photothermal efficiency of graphite nanofluid is } 122 \% \text { of that of the conventional solar } \\
\text { thermal collector }\end{array}$ & [48] \\
\hline
\end{tabular}

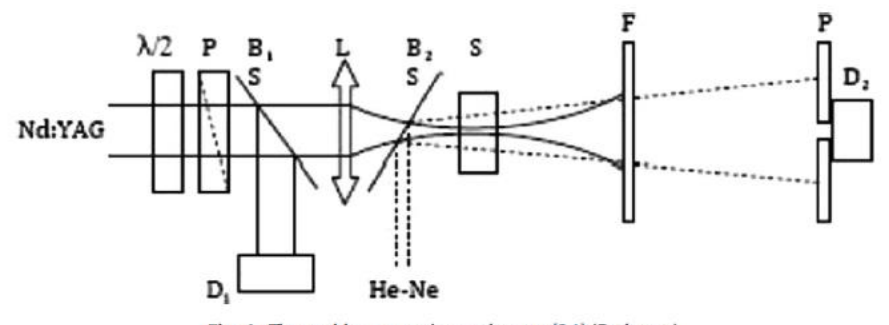

Fig. 4. Thermal lens experimental setup [24] (Redrawn).

development they assumed some parameters and those assumptions are as follows:

a) independent scattering;

b) all the particles are of the same size and are spherical; c) particle size is very small;

d) lower volume concentration ( $<0.6$ vol\%);

e) optical properties of nanoparticles are same as their bulk materials;

f) nanoparticles are of graphite or some other metal. 
Table 3

Experimental Extinction Index values of water, EG, PG and Therminol VP1 for various wavelengths at $25^{\circ} \mathrm{C}$ temperature [25].

\begin{tabular}{|c|c|c|c|c|c|c|c|c|c|}
\hline$\lambda(\mathrm{nm})$ & Water & EG & PG & VP1 & $\lambda(\mathrm{nm})$ & Water & EG & PG & VP1 \\
\hline 220 & $1.23 \mathrm{E}-7$ & $6.99 \mathrm{E}-7$ & $1.29 \mathrm{E}-6$ & $2.45 \mathrm{E}-4$ & 880 & $4.36 \mathrm{E}-7$ & $1.54 \mathrm{E}-7$ & $5.51 \mathrm{E}-7$ & $1.53 \mathrm{E}-7$ \\
\hline 240 & $6.34 \mathrm{E}-8$ & $2.88 \mathrm{E}-7$ & 5.41E-7 & $2.63 \mathrm{E}-4$ & 900 & 5.21E-7 & $3.98 \mathrm{E}-7$ & $6.3 \mathrm{E}-7$ & 0.00 \\
\hline 280 & $7.02 \mathrm{E}-8$ & $9.13 \mathrm{E}-8$ & $1.82 \mathrm{E}-7$ & $3.05 \mathrm{E}-4$ & 940 & $1.42 \mathrm{E}-6$ & 7.17E-7 & $5.24 \mathrm{E}-7$ & 0.00 \\
\hline 300 & $6.73 \mathrm{E}-8$ & $4.73 \mathrm{E}-8$ & $1.18 \mathrm{E}-7$ & $7.83 \mathrm{E}-5$ & 960 & $3.33 \mathrm{E}-6$ & $5.55 \mathrm{E}-7$ & 1.20E-6 & 0.00 \\
\hline 320 & $6.91 \mathrm{E}-8$ & $4.01 \mathrm{E}-8$ & $9.67 \mathrm{E}-8$ & $6.05 \mathrm{E}-6$ & 980 & 3.77E-6 & 1.30E-6 & $1.52 \mathrm{E}-6$ & 0.00 \\
\hline 340 & $7.18 \mathrm{E}-8$ & 3.33E-8 & $8.67 \mathrm{E}-8$ & $2.41 \mathrm{E}-6$ & 1000 & $3.25 \mathrm{E}-6$ & $1.72 \mathrm{E}-6$ & $1.56 \mathrm{E}-6$ & 0.00 \\
\hline 400 & $6.91 \mathrm{E}-8$ & $2.06 \mathrm{E}-8$ & $6.83 \mathrm{E}-8$ & $1.39 \mathrm{E}-7$ & 1060 & $1.25 \mathrm{E}-6$ & $1.62 \mathrm{E}-6$ & $1.08 \mathrm{E}-6$ & 0.00 \\
\hline 420 & $6.54 \mathrm{E}-8$ & $2.05 \mathrm{E}-8$ & $6.59 \mathrm{E}-8$ & $8.23 \mathrm{E}-8$ & 1080 & $1.27 \mathrm{E}-6$ & $1.42 \mathrm{E}-6$ & $9.00 \mathrm{E}-7$ & 0.00 \\
\hline 440 & 7.14E-8 & $1.97 \mathrm{E}-8$ & $6.32 \mathrm{E}-8$ & $3.86 \mathrm{E}-8$ & 1100 & $1.66 \mathrm{E}-6$ & $1.19 \mathrm{E}-6$ & $8.49 \mathrm{E}-7$ & $1.46 \mathrm{E}-7$ \\
\hline 460 & $7.11 \mathrm{E}-8$ & $2.12 \mathrm{E}-8$ & $6.27 \mathrm{E}-8$ & 0.00 & 1120 & $2.29 \mathrm{E}-6$ & $9.96 \mathrm{E}-7$ & $1.92 \mathrm{E}-6$ & $2.08 \mathrm{E}-6$ \\
\hline 480 & 7.09E-8 & $2.25 \mathrm{E}-8$ & $6.28 \mathrm{E}-8$ & 0.00 & 1140 & 5.41E-6 & 1.34E-6 & $3.60 \mathrm{E}-6$ & $1.50 \mathrm{E}-5$ \\
\hline 500 & $6.88 \mathrm{E}-8$ & $2.35 \mathrm{E}-8$ & $6.40 \mathrm{E}-8$ & 0.00 & 1160 & $1.06 \mathrm{E}-5$ & $3.16 \mathrm{E}-6$ & $8.72 \mathrm{E}-6$ & $2.02 \mathrm{E}-6$ \\
\hline 520 & $7.25 \mathrm{E}-8$ & $2.42 \mathrm{E}-8$ & $6.42 \mathrm{E}-8$ & 0.00 & 1180 & 1.15E-5 & 6.57E-6 & $8.22 \mathrm{E}-6$ & 5.10E-7 \\
\hline 560 & 7.37E-8 & $2.55 \mathrm{E}-8$ & $6.40 \mathrm{E}-8$ & 0.00 & 1220 & $1.17 \mathrm{E}-5$ & $1.13 \mathrm{E}-5$ & $6.75 \mathrm{E}-6$ & 1.13E-7 \\
\hline 580 & 7.37E-8 & $2.56 \mathrm{E}-8$ & $6.54 \mathrm{E}-8$ & 0.00 & 1240 & 1.12E-5 & 7.46E-6 & $5.67 \mathrm{E}-6$ & 0.00 \\
\hline 600 & $8.25 \mathrm{E}-8$ & $2.72 \mathrm{E}-8$ & $6.98 \mathrm{E}-8$ & 0.00 & 1260 & $1.08 \mathrm{E}-5$ & $6.39 \mathrm{E}-6$ & $4.58 \mathrm{E}-6$ & 0.00 \\
\hline 620 & $8.43 \mathrm{E}-8$ & $3.13 \mathrm{E}-8$ & 7.12E-8 & 0.00 & 1280 & $1.13 \mathrm{E}-5$ & 5.94E-6 & $3.70 \mathrm{E}-6$ & 0.00 \\
\hline 640 & $9.15 \mathrm{E}-8$ & $3.70 \mathrm{E}-8$ & $6.88 \mathrm{E}-8$ & 0.00 & 1300 & $1.36 \mathrm{E}-5$ & $4.66 \mathrm{E}-6$ & $3.71 \mathrm{E}-6$ & 0.00 \\
\hline 660 & $9.90 \mathrm{E}-8$ & $3.42 \mathrm{E}-8$ & 7.05E-8 & 0.00 & 1320 & $1.89 \mathrm{E}-5$ & $4.77 \mathrm{E}-6$ & $5.26 \mathrm{E}-6$ & 6.32E-7 \\
\hline 680 & $1.07 \mathrm{E}-7$ & $3.65 \mathrm{E}-8$ & $7.20 \mathrm{E}-8$ & 0.00 & 1340 & $2.84 \mathrm{E}-5$ & $6.57 \mathrm{E}-6$ & $1.21 \mathrm{E}-5$ & $1.20 \mathrm{E}-6$ \\
\hline 700 & $1.18 \mathrm{E}-7$ & $4.05 \mathrm{E}-8$ & $8.30 \mathrm{E}-8$ & 0.00 & 1360 & $3.87 \mathrm{E}-5$ & $1.12 \mathrm{E}-5$ & $1.61 \mathrm{E}-5$ & 1.34E-6 \\
\hline 720 & $1.43 \mathrm{E}-7$ & $5.39 \mathrm{E}-8$ & $1.47 \mathrm{E}-7$ & 0.00 & 1380 & $6.25 \mathrm{E}-5$ & $1.64 \mathrm{E}-5$ & $1.84 \mathrm{E}-5$ & $1.92 \mathrm{E}-6$ \\
\hline 740 & $2.11 \mathrm{E}-7$ & $1.03 \mathrm{E}-7$ & $1.73 \mathrm{E}-7$ & 0.00 & 1400 & $1.74 \mathrm{E}-4$ & $2.05 \mathrm{E}-5$ & $4.05 E-5$ & $2.52 \mathrm{E}-6$ \\
\hline 760 & $2.37 \mathrm{E}-7$ & $1.65 \mathrm{E}-7$ & $1.79 \mathrm{E}-7$ & 0.00 & 1420 & $2.95 \mathrm{E}-4$ & $4.68 \mathrm{E}-5$ & $6.73 \mathrm{E}-5$ & $2.44 \mathrm{E}-6$ \\
\hline 780 & $2.40 \mathrm{E}-7$ & $1.60 \mathrm{E}-7$ & $1.86 \mathrm{E}-7$ & 0.00 & 1440 & $3.52 \mathrm{E}-4$ & $7.80 \mathrm{E}-5$ & 7.86E-5 & $2.58 \mathrm{E}-6$ \\
\hline 800 & $2.38 \mathrm{E}-7$ & $1.60 \mathrm{E}-7$ & $1.88 \mathrm{E}-7$ & 0.00 & 1460 & $3.60 \mathrm{E}-4$ & $9.67 \mathrm{E}-5$ & $8.65 \mathrm{E}-5$ & $1.74 \mathrm{E}-6$ \\
\hline 820 & $2.64 \mathrm{E}-7$ & $1.65 \mathrm{E}-7$ & $8.80 \mathrm{E}-8$ & 0.00 & 1480 & $3.13 \mathrm{E}-4$ & $1.09 \mathrm{E}-4$ & $8.83 \mathrm{E}-5$ & $1.49 \mathrm{E}-6$ \\
\hline 840 & 3.10E-7 & 7.63E-8 & $1.08 \mathrm{E}-7$ & 0.00 & 1500 & $2.53 \mathrm{E}-4$ & $1.15 E-4$ & $8.83 \mathrm{E}-5$ & $1.34 \mathrm{E}-6$ \\
\hline
\end{tabular}

Table 4

Experimental Refractive Index and Density values of water, EG and their mixtures at various temperatures [26].

\begin{tabular}{|c|c|c|c|c|c|c|c|c|c|c|c|}
\hline Temp. (K) & $\begin{array}{l}\text { Molar Fraction } \\
\text { of EG }\end{array}$ & $\begin{array}{l}\text { Density } \\
\left(\mathrm{g} / \mathrm{cm}^{-3}\right)\end{array}$ & \multicolumn{3}{|c|}{ Refractive Index } & Temp. (K) & $\begin{array}{l}\text { Molar Fraction } \\
\text { of EG }\end{array}$ & $\begin{array}{l}\text { Density } \\
\left(\mathrm{g} / \mathrm{cm}^{-3}\right)\end{array}$ & \multicolumn{3}{|c|}{ Refractive Index } \\
\hline \multirow[t]{11}{*}{283.15} & & 0.9997 & 0.9997 & & & 293.15 & & 0.9982 & 1.3330 & & \\
\hline & 0.0312 & 1.0134 & & & 1.3448 & & 0.0312 & 1.0109 & & & 1.3429 \\
\hline & 0.0487 & 1.0203 & & & 1.3489 & & 0.0487 & 1.0177 & & & 1.3481 \\
\hline & 0.0677 & 1.0276 & & & 1.3541 & & 0.0677 & 1.0245 & & & 1.3528 \\
\hline & 0.1000 & 1.0390 & & & 1.3617 & & 0.1000 & 1.0351 & & & 1.3608 \\
\hline & 0.2250 & 1.0705 & & & 1.3855 & & 0.2250 & 1.0648 & & & 1.3841 \\
\hline & 0.3003 & 1.0832 & & & 1.3955 & & 0.3003 & 1.0766 & & & 1.3936 \\
\hline & 0.4038 & 1.0945 & & & 1.4059 & & 0.4038 & 1.0881 & & & 1.4038 \\
\hline & 0.5373 & 1.1045 & & & 1.4157 & & 0.5373 & 1.0978 & & & 1.4137 \\
\hline & 0.7232 & 1.1131 & & & 1.4246 & & 0.7232 & 1.1062 & & & 1.4225 \\
\hline & 1.0000 & 1.1203 & & & 1.4335 & & 1.0000 & 1.1132 & & & 1.4319 \\
\hline \multirow[t]{9}{*}{303.15} & & 0.9956 & 1.3320 & & & 313.15 & & 0.9922 & 1.3306 & & \\
\hline & 0.1622 & 1.0453 & & & 1.3722 & & 0.1622 & 1.0413 & & & 1.3708 \\
\hline & 0.2000 & 1.0544 & & & 1.3796 & & 0.2000 & 1.0480 & & & 1.3803 \\
\hline & 0.2250 & 1.0590 & & & 1.3820 & & 0.2250 & 1.0530 & & & 1.3810 \\
\hline & 0.3003 & 1.0703 & & & 1.3921 & & 0.3003 & 1.0639 & & & 1.3907 \\
\hline & 0.4038 & 1.0815 & & & 1.4017 & & 0.4038 & 1.0746 & & & 1.3991 \\
\hline & 0.5373 & 1.0909 & & & 1.4110 & & 0.5373 & 1.0840 & & & 1.4084 \\
\hline & 0.7232 & 1.0992 & & & 1.4197 & & 0.7232 & 1.0921 & & & 1.4172 \\
\hline & 1.0000 & 1.1039 & & & 1.4287 & & 1.0000 & 1.0984 & & & 1.4254 \\
\hline
\end{tabular}

Link to Full-Text Articles:

http://www.sciencedirect.com/science/article/pii/S1364032114009411 